\title{
Development of a Smart Scanner Trolley System for Intelligent Billing Solutions using RFID and IoT System
}

\author{
Zakiah Mohd Yusoff $^{1 *}$,Arni Munira Markom ${ }^{1}$, Nur Dalila Khirul Ashar ${ }^{1}$, Zuraida Muhammad $^{2}$ \\ ${ }^{1}$ Faculty of Electrical Engineering, UniversitiTeknologi MARA (UiTM), Cawangan Johor, KampusPasir Gudang, \\ Johor, Malaysia \\ ${ }^{2}$ Faculty of Electrical Engineering, UniversitiTeknologi MARA, KampusPulau Pinang,Pulau Pinang, Malaysia \\ *zakiah9018@uitm.edu.my
}

\begin{abstract}
Shopping at hypermarkets, which offer an enormous array of household goods and food, has become a part of everyday life. Customers typically place all intended purchases into a shopping cart or trolley, then queue at a billing counter for each item to be scanned and bagged. This process is often hectic and time-consuming. These problems are often exacerbated during peak times, such as the weekend or holiday periods. Typical wait times may reach 15 to 20 minutes or longer. However, the ubiquity of wireless communications has enabled the development of e-commerce smart products which could simplify this process. The objective of this project is to develop a smart scanner trolley system using Radio Frequency Identification (RFID) and an Arduino microcontroller. The user simply scans each item using an RFID reader. After finishing his shopping, the user can pay for his purchases using a loyalty card linked to a debit card. The Smart Trolley terminal will automatically send a receipt via text message using the Internet of Things (IoT). Registered customers are not required to provide personal information other than a scan of their loyalty cards. The aim of this system is to facilitate in-store shopping with a system which is scalable, inexpensive, and durable.
\end{abstract}

Key words : RFID, scanner trolley system, bar code, internet of thing IoT.

\section{INTRODUCTION}

Supermarkets have become a common destination for the purchase of food products, clothing, and appliances. Consumers increasingly desire a safer, more convenient shopping experience. Conventional checkout counters are inconvenient for consumers, especially during peak times, and are labor-intensive, leading to higher costs. Long wait times contribute to customer dissatisfaction [1-3]. This is often due to the use of slower traditional methods for invoice generation [4-6]. Surveys have shown that a majority of customers are not willing to wait in a long queue to buy a few products, and may even abandon their trolley without completing the transaction.

Supermarkets must make improvements to their billing systems to ensure that their customers remain satisfied with their shopping experience [4] [6]. Several attempts have been made in the past few decades to address the problem of long queues in checkout lines. For example, self-checkouts have improved the shopping experience and remain popular among retailers due to decreased overhead costs [5] [7]. Additionally, smart shopping carts have been deployed which can display the total price of all items in a shopping cart, increasing convenience and customer confidence [6].

The ubiquity of advanced technology has increased consumer acceptance of electronic gadgets such as barcode scanners and RFID readers, as encountered in the context of the shopping mall [2- 3]. For example, Maulana, et al. [8] examined the effectiveness of the Zigbee shopping trolley application. The system relays information concerning purchased goods to a central server. Zheng, et al. [8] investigated a smart checkout system using Radio Frequency Identifier (RFID) tags which allows buyers to protect their privacy by disabling the tags [9-11]. These technologies serve as an important opportunity for retailers to provide increasingly personal service to an increased number of customers, while reducing costs and wait times [12] [ 10].

Chen, et al. [13] [9- 10] developed a novel way to toggle an RFID tag off and re-enable it when needed. Their system allows for an RFID tag attached to a customer's membership card to be detected by an RFID reader attached to a shopping trolley. A smartphone application acts as a barcode scanner. A barcode is generated which is send to the Arduino through a Bluetooth module. The Arduino interfaces with a Memory Unit, which contains information such as a product description, price, and stock count [10]. The results are then displayed on an LCD screen attached to the trolley [1][9][14-15].

RFID technology has become increasingly popular as an alternative to barcode systems [5][16-18]. Panasonic introduced a cashier-free convenience store concept using an RFID-enabled basket and UHF RFID tags on times. The technology has rapidly entered the mainstream in Malaysia 
in industries as diverse as logistics, transport, and manufacturing. In Sri Lanka and most South Asian countries, RFID technologies in retail have reduced labor requirements and customer purchase times and led to higher customer satisfaction [5][19-20].

RFID systems use transponders attached to individual items to store and retrieve information about the items [10]. RFID implementations can be broadly distinguished as active or passive [11]. Activated tags require an external power source and can be read from a further distance than passive tags, which are powered by the reader itself. For example, the 'Smart Tag' used on toll booths in Malaysia is an active tag, whereas passive tags are often incorporated into product packaging.

Smart Trolley Systems which incorporate these technologies offer numerous benefits to customers and retailers alike. While customers avoid long queues at the billing counter and thus enjoy faster and more convenient shopping, the retailer can achieve increased traffic with decreased labor requirements [1] [6][21][ 12]. In this paper, we have developed a Smart Trolley System which produces a list of items placed in a trolley for presentation at the billing counter for payment. The system also allows payment through a smartphone application.

The system works as follows. The user initiates the system by pressing a green button. Then, RFID tags for each item to be purchased are scanned using an RFID reader. The scanned items are displayed on an LCD screen. To cancel a scan, the user can press a red button on the device. When the user is finished shopping, she presses a yellow button to generate a display of the total price for all scanned items on the LCD screen. A receipt is also sent through a linked smartphone application. Payment can then be made via a loyalty card linked to a debit card.

\section{METHODOLOGY}

\subsection{Block Diagram}

The microcontroller used for this 'RFID Scanner Trolley System' is the Arduino Mega, as shown in Figure-1. It has two inputs, namely the RFID RC522 reader and a push button system. System outputs include a 20 X 4 liquid crystal display (LCD), buzzer and light emitting diode (LED). A Wi-Fi Node MCU is used to send the total spent to the user's smartphone. The Smart Trolley System also incorporates a loyalty card which is scanned by the RFID reader for payment. A diagram of the system is provided in Figure 1 below.

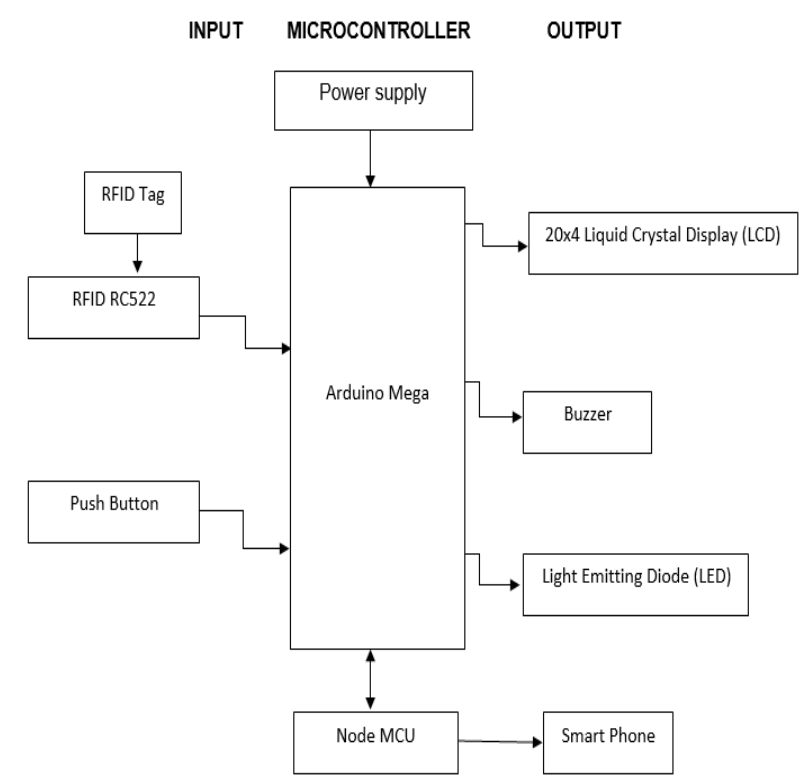

Figure 1:Block diagram of the RFID Scanner Trolley System

\subsection{System Flowchart}

Figure2 contains a flowchart detailing how the system functions. When the start button is pressed, the system displays, "Welcome to VIXX Supermarket". The user must push an green button to continue. The user may then begin to scan items. To cancel an item, the user presses the red button, which resets the system to the first stage. To view a total of the prices of all scanned items on the LCD screen, the user presses the yellow button.

After the total price of all items is displayed, the user may scan an RFID-enabled loyalty card. The LCD then displays the name of the user and the current balance of the loyalty card. The system will then deduct the total amount and display the remaining balance. The user will also receive a receipt through the linked smartphone application. 


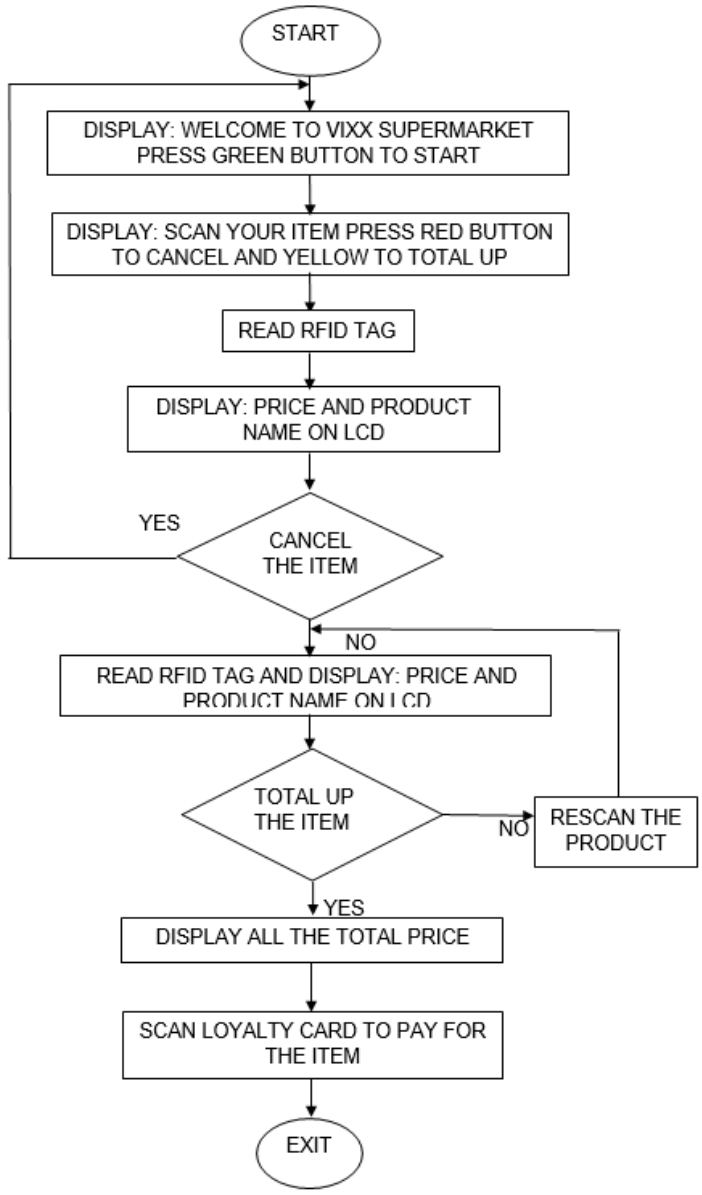

Figure 2: Flowchart of the RFID Scanner Trolley System

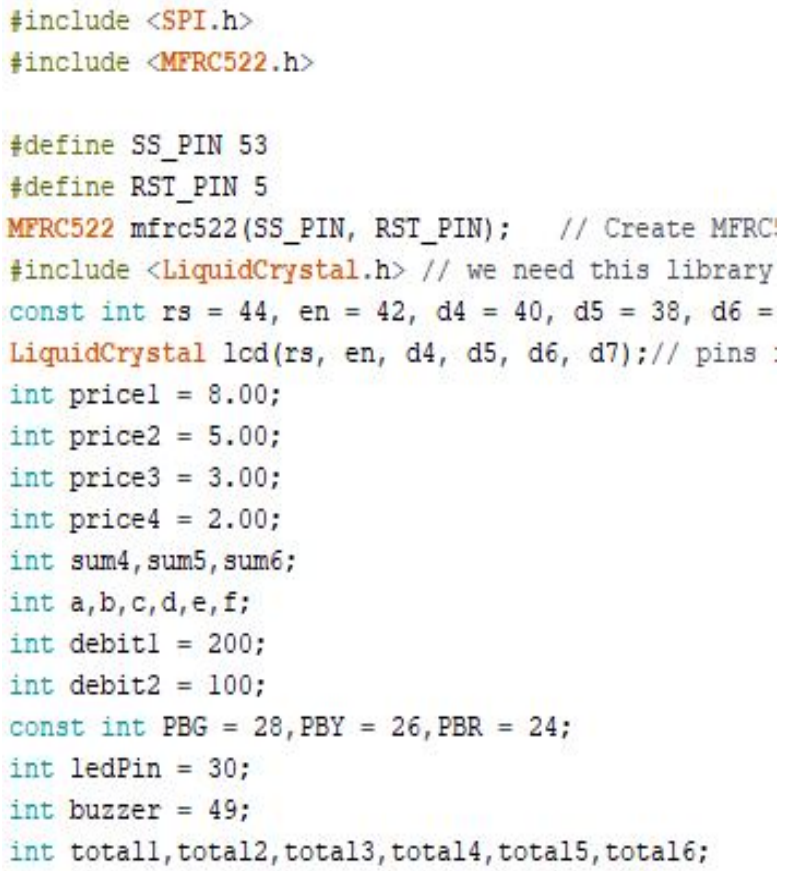

Figure 3 : Coding for VIXX Supermarket
This project consists of five major parts: block diagram, flowchart, schematic diagram, hardware design, testing and debugging.

Figure 3 shows an example of the coding for RFID scanner trolley using Arduino programming. Libraries are included for the RFID system and the LCD. Additionally, the pin for each component is declared. Int price refers to the price of a scanned item. The int sum is declared for use in the void loop. Int debit is refers to the value stored on the loyalty card. Const int values PBG, PBY and PBR refer to the push buttons. The int led pin refers to the LED and int buzzer refers to the buzzer.

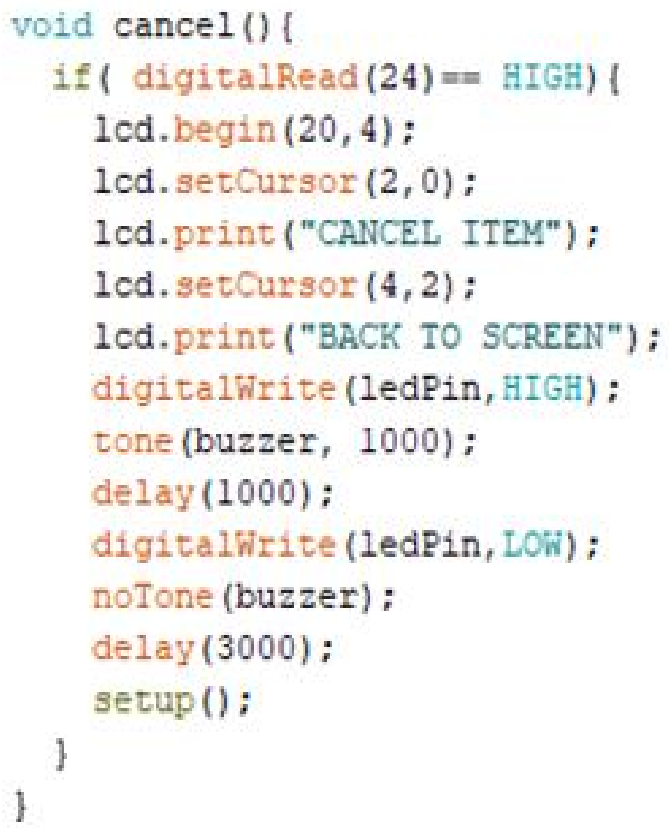

Figure 4: Coding for void cancel

'Void cancel' refers to canceling an item. When the red push button is pressed, the LCD will display 'cancel item' and return to the first screen. The LED will light and the buzzer will sound. The cancel is put at the end of the void loop.

\subsection{Schematic Diagram}

Figure 5 shows a schematic diagram for this RFID Scanner Trolley System using Proteus software. The schematic depicts the LCD, RFID, three push buttons, LED, and the buzzer. The system has two input types, namely the RFID scanner and three push buttons. The first button is the start button; the second button is the cancel button; and the final button is the 'total' button. The outputs include an LCD, LED and buzzer. The LED and buzzer will turn on when any buttons are pressed. The LCD will show a display when the push button is pushed or when an RFID tag or RFID card is scanned. The microcontroller that controls the overall system is the Arduino Mega. 


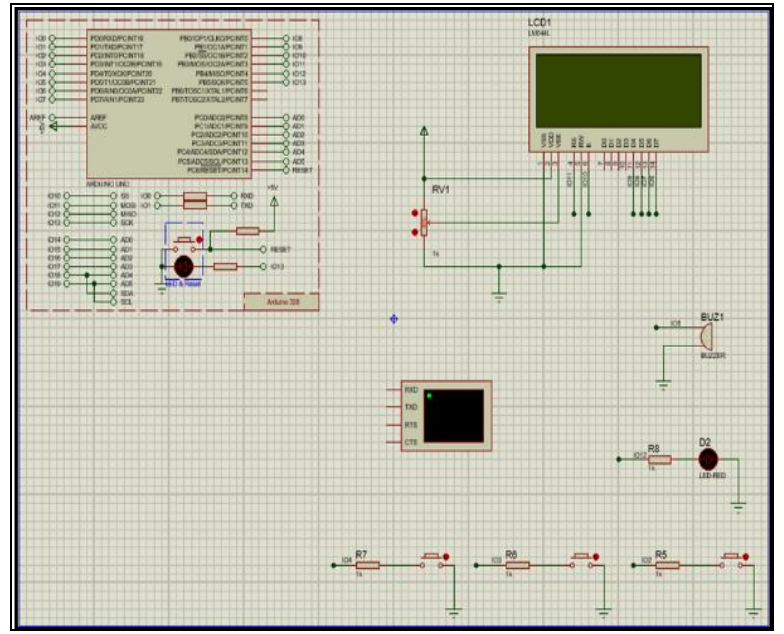

Figure 5 : Schematic diagram

\subsection{Hardware Design}

Figure 6 shows the printed circuit board (PCB) layout design in Proteus. To arrange each component on the PCB, they must be measured to ensure that they do not overlap. Connections between each component must also not overlap. Lines cannot form $90^{\circ}$ turns, because current cannot flow through a $90^{\circ}$ turn.

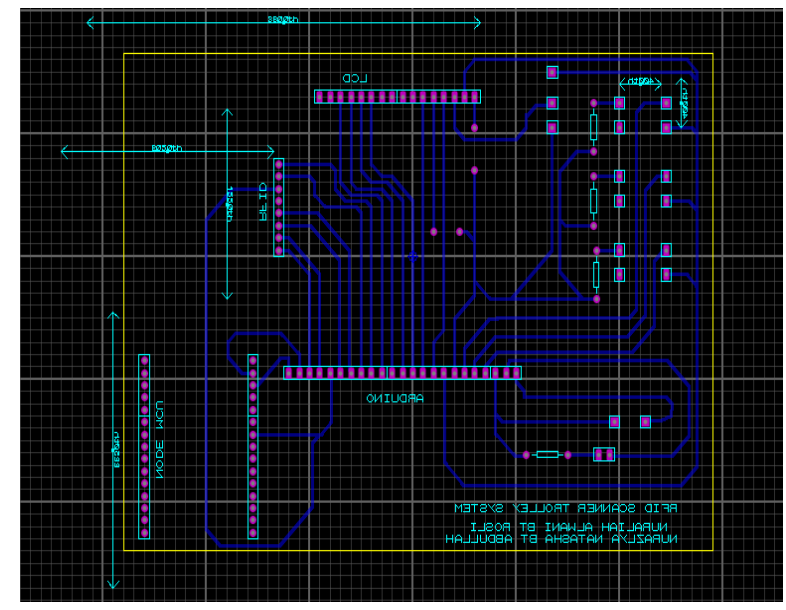

Figure 6 : Printed Circuit Board (PCB) Layout

Figure 7 shows the hardware design of the Smart Trolley System. The LCD, RFID, push button, LED and buzzer are placed outside the box so that the user can easily scan items and see the LCD. The user also can easily press the push buttons. When a button is pressed, the LED will light up and the buzzer will produce a sound to alert the user and ensure that the button is working.

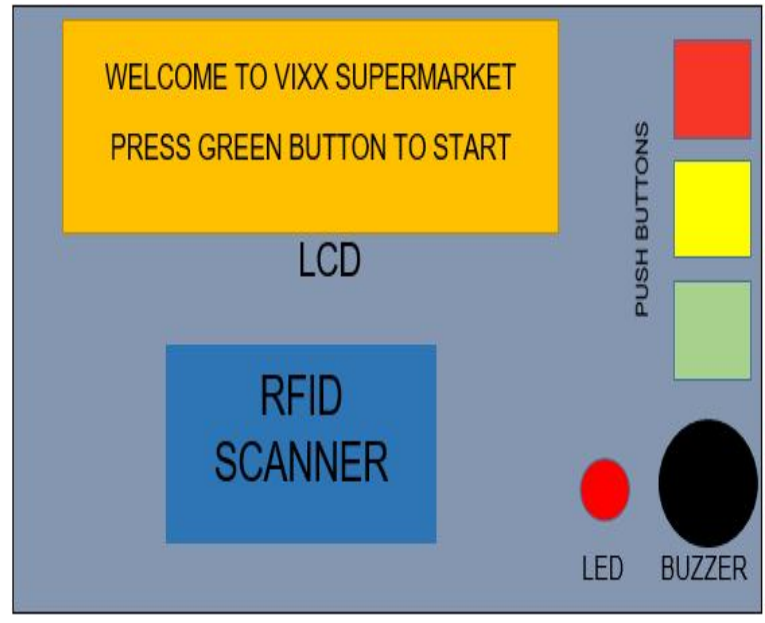

Figure 7: Hardware Design

\subsection{Testing and Debugging}

In the testing and debugging phase, the system connections and source code were verified. For the RFID reader, the source code was tested numerous times to ensure the ability of the RFID reader to read the tags. After reading the tags, the in hex file for each tag was copied and pasted inside the source code to initialize the name of each item and its price. The hex files were obtained by scanning each RFID tag and copying each value. Additionally, pressing the yellow button was intended to calculate the total value of all prices. Testing and debugging the code used to total the prices of all scanned items took a long time.

Finally cane the testing and debugging of the connection of the push button. After troubleshooting, the connection of the push button was changed from 4 to 2 pins. One pin was connected to a resistor and then connected to the output pin in the Arduino while the other pin was connected to the Arduino's 5V input source pin.

Figure 7 shows the top view of the proposed board game where there are 64 RG LEDs to represents players' chips, two joysticks for the player to control the movement of the chip, and a push button to end and reset the game.

\section{RESULTS AND DISCUSSION}

The results are divided into two sections, consisting of a simulation on the Proteus of the Arduino software, and the prototype results.

\subsection{Simulation Result}

i. LCD display "Welcome to Aliyong Market" 


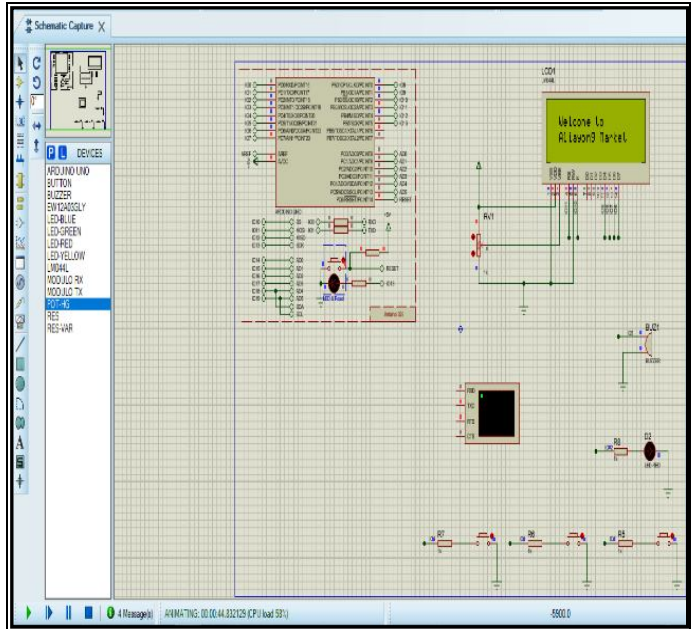

Figure 8: Simulation Result I

ii. The LCD displays, "Please scan your item"

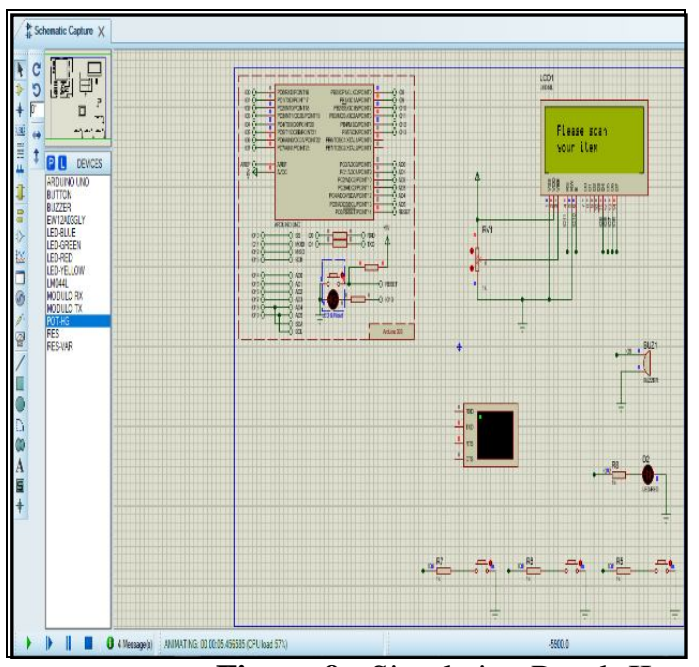

Figure 9: Simulation Result II

iii. The LCD displays, "THANK YOU"

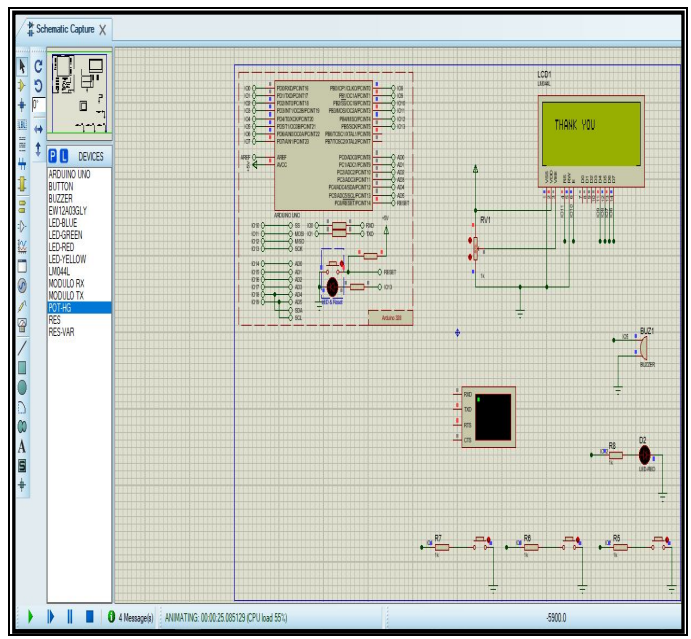

Figure 10: Simulation Result I

\subsection{Prototype Result}

Figure 11 shows a prototype of the RFID Scanner Trolley System. The system starts by displaying, "Welcome to VVIX Supermarket". The user presses the green button to proceed to the next step. The user scans each item's RFID tag in the RFID reader. These data are transferred to the Arduino Mega microcontroller, which displays the name and price for each scanned item on the LCD. The user is given a choice whether to cancel an item or to total the prices of all items scanned.

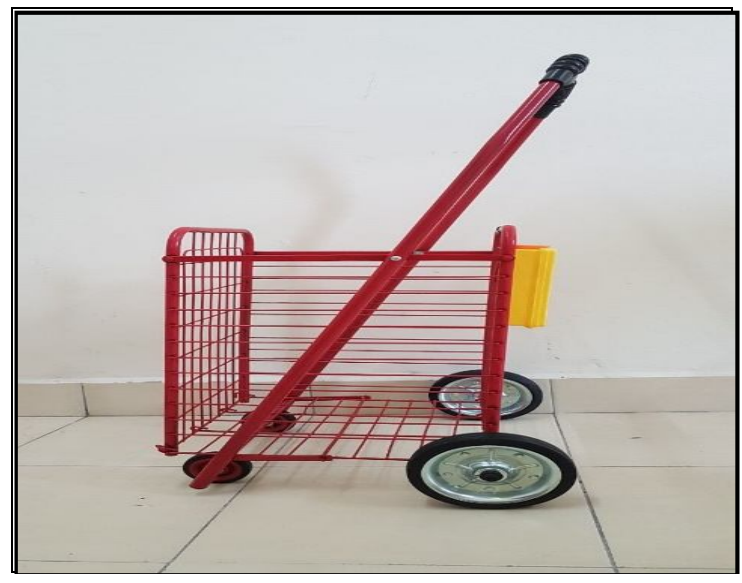

Figure 11: Prototype

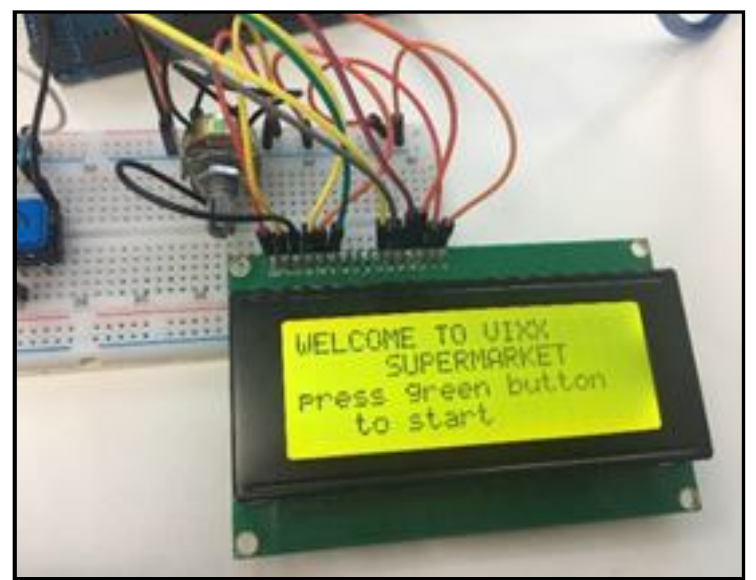

Figure 12

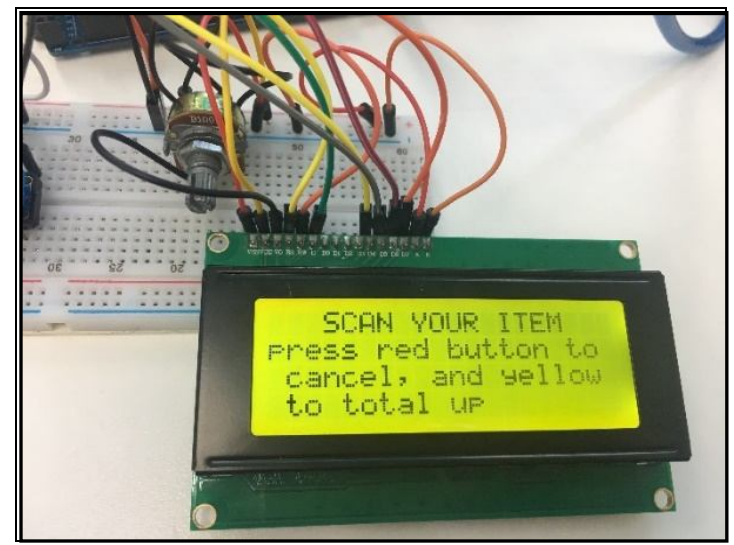

Figure $12 \& 13$ : Output for VVIX Supermarket 


\section{CONCLUSION}

RFID Scanner Trolley System is a revolutionary mobile self-checkout system which provides users flexibility in their shopping transactions. It is designed to be highly efficient and fully synchronized with retailers' current systems. Users will appreciate its speed and convenience, especially during busy periods such as weekends and holidays. The system is fun and user-friendly. The system allows constant monitoring to ensure that stock counts are up-to-date, improving decision making by management. This project can be further improved by reducing the size of the prototype and simplifying the system. Retailers can incorporate this inexpensive, efficient technology into their systems to improve customer retention. In the academic context, the output from this study will help in improving engineering efforts to bring existing technologies to end users. The efficiency of the proposed IoT concept will spur development in manufacturing as well. An affordable RFID Smart Trolley System allows less human intervention in processing data and will boost operational efficiency. Naturally, all findings in this research will be disseminated to the public.

\section{ACKNOWLEDGEMENT}

$\begin{array}{cccc}\text { This research is } & \text { funded } & \text { by } \\ \text { GeranPenyelidikanBestariSepadananFasa } & 1 / 2020 & \text { by }\end{array}$ UniversitiTeknologi MARA (UiTM) Cawangan Johor.

\section{REFERENCES}

[1] L. Wu, S. Liu, B. Zhao, W. Wu, and B. Zhu, "The research of the application of the binary search algorithm of RFID system in the supermarket shopping information identification," Eurasip J. Wirel. Commun. Netw., vol. 2019, no. 1, 2019, doi: 10.1186/s13638-019-1343-2.

[2] N. Jia, "Design of Fast Supermarket Shopping Based on Internet of Things," Proc. - 2017 Int. Conf. Robot. Intell. Syst. ICRIS 2017, pp. 112-115, 2017, doi: 10.1109/ICRIS.2017.35.

[3] M. Li, S. Gu, G. Chen, and Z. Zhu, "A RFID-based intelligent warehouse management system design and implementation," Proc. - 2011 8th IEEE Int. Conf. E-bus. Eng. ICEBE 2011, pp. 178-184, 2011, doi: 10.1109/ICEBE.2011.28.

[4] A. Sutagundar, M. Ettinamani, and A. Attar, "Iot Based Smart Shopping Mall," Proc. 2nd Int. Conf. Green Comput. Internet Things, ICGCIoT 2018, pp. 355-360, 2018, doi: 10.1109/ICGCIoT.2018.8752971.

[5] P. Tharaneetharan, M. Shafni, F. F. Marikar, K. D. S. Thiwanka, and S. G. S. Fernando, "QB - (Quick Buy) - Convenient Modern Shopping System Based on RFID Technology with Indoor Maps," Compusoft, vol. 3, no. 10, pp. 1172-1178, 2014.

[6] C. Technologies, "RFID based Smart Shopping: An Overview," 2014.

[7] T. Athauda, J. C. L. Marin, J. Lee, and N. C. Karmakar, "Robust Low-Cost Passive UHF RFID Based Smart Shopping Trolley," IEEE J. Radio Freq. Identif., vol. 2, no. 3, pp. 134-143, 2018, doi: 10.1109/jrfid.2018.2866087.

[8] A. Maulana, "Implementasi Wireless Sensor Network untukMengurangiAntrianKasir," presented at the Seminar Nasional TeknologiInformasi dan Multimedia, 2014.

[9] F. Zheng, et al., "The Introduction and Design of a New Form of Supermarket: Smart Market," presented at the International Symposium on Information Engineering and Electronic Commerce, 2009.

[10] Y.-Y. Chen, et al., "A Secure RFTD Deactivation/Activation Mechanism For Customer Service And Consumer Shopping," presented at the International Conference on Broadband and Wireless Computing, Communication and Applications, 2011.

[11] E. Maini and J. Shettar, "Wireless Intelligent Billing Trolley for Malls," International Journal of Scientific Engineering and Technology vol. 3, pp. 1175-1178 2014

[12] H. S. Bedi, et al., "Smart Trolley using Smart Phone and Arduino," Journal of Electrical \& Electronic Systems, vol. 6, 2017.

[13] S. Dhauta and S. Kapoor, "Interactive intellegent shopping cart using RFID and ZIGBEE modules," in 2017 International Conference on I-SMAC (IoT in Social, Mobile, Analytics and Cloud) (I-SMAC), 2017, pp. 764-7

[14] G. Prerna, et al., "Smart Billing Trolley using RFID \& LIFI," International Journal of Current Trends in Science and Technology, vol. 8, pp. 41-46, 2018.

[15] C. Shih, et al., "Smart Shopping An Automatic Smart Shopping Cart Deployment Framework based on Pattern Design," presented at the IEEE 15th International Symposium on Consumer Electronics, 2011.

[16] S. Dhauta, "And ZIGBEE Modules," pp. 764-769, 2017.

[17] B. Mary and C. O. Connor, "ShopRite to Roll Out Second Test of RFID Shopping Carts ShopRite to Roll Out Second Test of RFID Shopping Carts," pp. 1-2, 2008.

[21] Nallarasan, V and Kottilingam, K., "Enhanced security in iot networks using ensemble learning methods-a cognitive radio approach", International Journal of Emerging Trends in Engineering Research, vol. 8 no.8, pp. 4405-4412, 2020

[19] T. Qu, H. D. Yang, G. Q. Huang, Y. F. Zhang, H. Luo, and W. Qin, "A case of implementing RFID-based real-time shop-floor material management for household electrical appliance manufacturers," J. Intell. Manuf., vol. 23, no. 6, pp. 2343-2356, 2012, doi: 10.1007/s10845-010-0476-2.

[20] Anchal and Mittal, P., "Iot based intelligent modeling of smart home parking environment", International Journal of Emerging Trends in Engineering Research, vol. 8, issue 7, pp. 3442-3446, 2020

[21] P. T. Sivagurunathan, P. Seema, M. Shalini, R. Sindhu, and C. Engineering, "Smart Shopping Trolley Using Rfid," vol. 118, no. 20, pp. 3783-3786, 2018. 